\title{
Effect of medium chain triglycerides (MCT) on jejunal mucosa mass and protein synthesis
}

\author{
S Schwartz, M Farriol, E Garcia-Arumi, A L Andreu, J López Hellín, M A Arbós
}

\section{Abstract}

The effects of medium chain triglycerides (MCT) on jejunal mucosa mass and protein synthesis were compared with results from previous experiments with rats fed by parenteral nutrition or enteral nutrition. Other published studies have also been analysed. Three experimental models were studied. In the traumatic model, production of a femoral fracture was followed by Kirschner pin insertion into the medullary canal of both fragments at reduction. (Forty rats were fed enteral nutrition and 93 were given parenteral nutrition.) A second model entailed resection under ether anaesthesia using the technique described by Higgins. (Fifty five rats were fed enteral nutrition and 28 with parenteral nutrition.) A third model entailed a terminolateral portocaval shunt under anaesthesia with pentobarbital. (Sixty nine rats were treated this way and then given enteral nutrition.) Proportions of medium chain/long chain triglycerides (LCT) were as follows: $0 / 100,20 / 80$, $40 / 60,50 / 50$, and $92 / 8$ for enteral nutrition and $0 / 100,30 / 70,50 / 50$, and $70 / 30$ for parenteral nutrition. Faecal losses of $\alpha$ amino nitrogen, protein, total fats, and free fatty acids were analysed together with the quantitative intake, weight gain of the rats, jejunal mucosal mass, and protein synthesis in relation to the MCT proportion ingested or given by enteral nutrition or parenteral nutrition. From analysis of our results and those of others, several conclusions could be drawn. Firstly, the route of administration of MCT is extremely important and enterocytes might be considered one of the main target sites. Secondly, a high proportion of MCT (more than $80 \%$ ) offers no advantage for jejunal mucosa and produces undesirable side effects. Thirdly, the effect of MCT on jejunal mucosal protein synthesis depends on the metabolic state. Finally, an increase in jejunal mucosal mass directly correlated with MCT concentrations, but no correlation was found between mass and protein synthesis. A positive correlation, however, between MCT proportion and enzyme activity (alkaline phosphatase and sucrase) in the brush border membrane was seen as well as a positive correlation with the concentration of phospholipids in the microvilli.

(Gut 1994; supplement 1: S39-S41)
In $1986,{ }^{1}$ we suggested that the qualitative intake of energy substrates influenced the rate of jejunal mucosal protein synthesis. This provided the possibility for organ specific nutrition, while preserving an overall rate of protein synthesis appropriate to the metabolic state. Further studies suggested that the effect was also dependent on the route of nutrient administration. ${ }^{2}$ Three experimental models were used in rats. Firstly, ${ }^{23}$ the traumatisation model entailed production of a femoral fracture followed by Kirschner pin insertion into the medullary canal of both fragments at reduction. The second method required $70 \%{ }^{45}$ liver resection under ether anaesthesia using the technique described by Higgins. The third model entailed terminolateral portocaval shunt under anaesthesia with pentobarbital.

The first model presented a postsurgical stress flow phase with increase in both tissue synthesis and catabolism. This increase is related to the severity of stress and the nutritional state. Protein synthesis presents characteristic dynamics, which reach a maximum around the third postoperative day; protein breakdown is highly sensitive to food supply. The second model represented increased protein synthesis and a decrease in catabolism 12 hours after surgery. In neither of these models was a deficit in endogenous carnitine synthesis seen. The third model, however, produced a $40 \%$ decrease in liver mass and considerably reduced endogenous carnitine synthesis, even with a dietary intake rich in its precursors, lysine and methionine.

\section{Materials and methods}

In the trauma model with enteral nutrition, Sprague-Dawley rats (initial weight mean (SD) $180(10 \mathrm{~g})$ were divided into four groups $(n=40)$. Each group received an identical modular diet, which only differed in the medium chain triglycerides (MCT)/long chain triglycerides (LCT) ratio. The gross composition of the diets (gram/gram nitrogen) was carbohydrates, 15.62 ; lipids, 9.37 ; and proteins, 5.08, which corresponds with (\% wt/wt) proteins 20 , lipids 30 , carbohydrates 50 . The variable composition of MCT/LCT was $20 / 80$ (control group), 40/60, 60/40, and $92 / 8$ for each group, respectively. Enteral food and water were given 'ad libitum' for six days. In the trauma model with parenteral nutrition, the Sprague-Dawley rats $(n=93)$ with body weights between 148 and 177 grams were also divided into four groups: group 1 (control), LCT alone; group 2, MCT/LCT 30/70; group 3, MCT/LCT 50/50; group 4, 
TABLE I Trauma model-body weight increase

\begin{tabular}{ll}
\hline Group & Weight increase $(g)$ \\
\hline 1 (control) & $11 \cdot 7(3 \cdot 9)$ \\
2 & $14 \cdot 1(2 \cdot 8)$ \\
3 & $16 \cdot 4(3 \cdot 6)^{\star}$ \\
4 & $10 \cdot 3(4 \cdot 7)$ \\
\hline
\end{tabular}

$\star$ Statistically significant difference $v 1(\mathrm{p}<0.025)$ and $v 4$ $(p<0 \cdot 01)$. Values expressed as mean (SD).

TABLE II Trauma model-jejunal mucosa protein synthesis

\begin{tabular}{llc}
\hline & \multicolumn{2}{l}{ Protein synthesis } \\
\cline { 2 - 3 } Group & $m g / d / g$ organ wt & $m g / d / m g R N A$ \\
\hline 1 (control) & $137(38)$ & $43(9)$ \\
2 & $210(28)^{\star}$ & $143(55)^{\star}$ \\
4 & $159(20)$ & $88(15)$ \\
\hline
\end{tabular}

*Statistically significant differences $v 1,3$, and $4(\mathrm{p}<0.001)$. Values expressed as mean (SD).

TABLE III Trauma model-jejunal mucosa mass and protein synthesis

\begin{tabular}{llc}
\hline Group & Mucosal weight & $\begin{array}{c}\text { Protein synthesis } \\
(m g / d / g \text { tissue) }\end{array}$ \\
\hline 1 (control) & $0.47(0 \cdot 07)$ & $63 \cdot 8(6 \cdot 5)$ \\
2 & $0.44(0.06)$ & $94 \cdot 1(2 \cdot 7)$ \\
3 & $0.61(0 \cdot 08)$ & $84 \cdot 4(16 \cdot 4)$ \\
4 & $0.78(0.09)$ & $109 \cdot 3(48 \cdot 6)$
\end{tabular}

Values expressed as mean (SD).

TABLE IV Trauma model-jejunal protein synthesis

\begin{tabular}{lll}
\hline & \multicolumn{2}{l}{ Protein synthesis } \\
\cline { 2 - 3 } Group & Fractional rate $(\% / d)$ & $m g / d$ \\
\hline 1 (control) & $193(28)^{\star}$ & $75 \cdot 1(20)^{\star \star}$ \\
2 & $161(11)$ & $63 \cdot 5(14 \cdot 2)$ \\
3 & $132(23)$ & $48 \cdot 0(12 \cdot 3)$ \\
4 & $166(19)$ & $71 \cdot 1(13 \cdot 7)$
\end{tabular}

$\star$ Statistically significant differences $v$ groups 2,3 , and 4

$(\mathrm{p}<0.05) .{ }^{\star}$ Statistically significant differences $v$ groups 2 and $3(p<0 \cdot 05)$. Values expressed as mean (SD).

MCT/LCT 70/30. All groups received $1 \cdot 8 \mathrm{~g}$ of nitrogen $/ \mathrm{kg} /$ day and $350 \mathrm{kcal} / \mathrm{kg} /$ day with a carbohydrates/lipid ratio of $75 / 25 \%$, equivalent to $330 \mathrm{ml} / \mathrm{kg} /$ day infusion. Nutrition mixtures were supplemented with a polyvitamin solution. All rats received the same energy and nitrogen intake for four days. In the group with $70 \%$ partial hepatectomy and enteral nutrition, four groups of SpragueDawley rats $(n=55)$ with an initial weight of 150-170 grams were studied. They were fed 'ad libitum' for eight days with the same diets as the trauma group. In the group with $70 \%$ partial hepatectomy and parenteral nutrition, two groups of Sprague-Dawley rats $(n=28)$ with an initial weight of 150 grams, were studied. The proportion of carbohydrates/ lipids was $75 / 25 \%$. One group received only LCT and the other an oil mixture of $50 / 50 \%$ MCT/LCT. The rats were fed the diet for seven days. In the group with terminolateral portocaval shunt and enteral nutrition, four groups of Sprague-Dawley rats $(n=69)$ with an initial body weight of 250 (25) grams were studied. The were fed 'ad libitum' with the following proportions of MCT/LCT: 0/100 (control group); 20/80; 50/50, and 80/20.

\section{Results and discussion}

In the trauma model with enteral nutrition, the weight of the rats increased in direct correlation with the MCT content, except for the fourth group (Table I). The quantitative intake was significantly lower only for the fourth group, with high MCT content (92\%). Faecal losses of $\alpha$ amino nitrogen, proteins, total fats, and free fatty acids were minimal and negligible, which showed good absorption of the diet in all groups. We saw that for jejunal mucosa, the highest rate of protein synthesis occurred in rats fed a diet containing $40 \%$ lipid as MCT a day (Table II). There was no correlation, however, between the jejunal mucosa mass and the daily rate of protein synthesis (Table III). These results suggest firstly, the greatest stimulus of protein synthesis/gram of tissue was obtained with the MCT/LCT proportion of 40/60, though no differences were found on absolute synthesis; secondly, the increase in jejunal mass directly correlated with the MCT content of the diet; thirdly, no correlation was found between mass and the function of this mass on protein synthesis; and finally, a high proportion of MCT in the diet seems to confer no metabolic advantage to the jejunal mucosa.

In the trauma model groups with parenteral nutrition, no statistically significant differences were seen either in urea or creatinine excretion. In jejunum, group 1 (LCT) (control) showed the highest rate of daily protein synthesis and fractional synthesis rate (Table IV). These results differ from those previously found in rats fed 'ad libitum' with different diets differing in the ratio of MCT/LCT. Thus the route of lipid administration may be of great significance to the nutrition of mucosal cells of the intestine.

In the hepatectomy model with enteral nutrition, all animals gained weight, even those fed a diet with high MCT content (groups: 1, $+15 \cdot 7 ; 2,+17 \cdot 5 \% ; 3,+21 \cdot 6 \% ; 4,+25 \cdot 1 \%$; $\mathrm{p}<0.001$ group $4 v$ groups 1 and 2 ), although this group ingested significantly fewer calories. As before, we saw a positive correlation between jejunal mucosal weight and the increase of MCT in the diet (groups: $1,0.43 \mathrm{~g}$; $2,0.48 \mathrm{~g} ; 3,0.55 \mathrm{~g} ; 4,0.69 \mathrm{~g} ; \mathrm{p}<0.001$ group $1 v$ groups 3 and 4 ). No differences in protein synthesis/gram of tissue and protein synthesis/day were seen (Table V). These results suggest that although quantitative energy intake progressively decreases as MCT content increases, the rate of weight gain rises progressively and correlates with the amount of dietary MCT. Indeed, the increase in jejunal mucosal mass directly correlated with MCT proportion, whereas, jejunal protein synthesis was relatively unaffected by this dietary change.

In the hepatectomy model with parenteral nutrition, the proportion of MCT in lipid intake had no effect on growth rate or jejunal mass. If $50 \%$ of lipid was given as MCT, however, mucosal protein content and protein synthesis were significantly higher than in the other groups (Table VI, VII). These data suggest that despite a lack of luminal nutrients, the mucosa can respond to qualitative differences in parenteral lipid supply. 
TABLE V Hepatectomy model-jejunal protein synthesis

\begin{tabular}{lll}
\hline & \multicolumn{2}{l}{ Protein synthesis } \\
\cline { 2 - 3 } Group & $m g / d$ & $m g / d / g$ organ wt \\
\hline 1 (control) & $74 \cdot 8(18 \cdot 8)$ & $174 \cdot 1(35 \cdot 6)$ \\
2 & $76 \cdot 2(34 \cdot 0)$ & $155 \cdot 2(49 \cdot 1)$ \\
3 & $67 \cdot 2(8 \cdot 5)$ & $122 \cdot 4(20 \cdot 8)$ \\
4 & $118 \cdot 6(43 \cdot 5)$ & $175 \cdot 5(58 \cdot 7)$ \\
\hline
\end{tabular}

Values expressed as mean (SD).

TABLE VI Hepatectomy model-jejunal protein content

\begin{tabular}{lll}
\hline Group & Organ weight $(g)$ & $\begin{array}{l}\text { Organ weight/ } \\
100 \text { g body } \\
\text { weight }\end{array}$ \\
\hline 1 (control) & $102(14)$ & $29 \cdot 8(5 \cdot 5)$ \\
2 & $116(9)^{\star}$ & $35 \cdot 0(5 \cdot 8)^{\star \star}$
\end{tabular}

${ }^{\star} \mathrm{p}<0.005,{ }^{\star \star} \mathrm{p}<0.02$. Values expressed as mean (SD).

TABLE VII Hepatectomy model-jejunal mucosa protein synthesis

\begin{tabular}{lll}
\hline \multirow{2}{*}{ Group } & \multicolumn{2}{l}{ Protein synthesis } \\
\cline { 2 - 3 } 1 (control) & Fractional rate \%/d & $m g / d$ \\
\hline 2 & $132 \cdot 5(18 \cdot 6)$ & $41 \cdot 5(5 \cdot 9)$ \\
& $176 \cdot 4(15 \cdot 0)^{\star}$ & $60 \cdot 1(11 \cdot 5)^{\star \star}$ \\
\hline
\end{tabular}

${ }^{\star} \mathrm{p}<0 \cdot 005,{ }^{\star \star} \mathrm{p}<0 \cdot 02$. Values expressed as mean (SD).

TABLE VIII Portacaval shunt model-jejunal mucosa weight

\begin{tabular}{ll}
\hline Group & fejunal mucosa weight $(g)$ \\
\hline 1 (control) & $0.54(0 \cdot 06)^{\star}$ \\
2 & $0.72(0 \cdot 19)^{\star \star}$ \\
3 & $0.79(0 \cdot 05)$ \\
4 & $0.97(0 \cdot 16)$
\end{tabular}

${ }^{\star} \mathrm{p}<0.001 v$ groups 3 and $4,{ }^{\star \star} \mathrm{p}<0.001 v$ group 4 . Values expressed as mean (SD).

TABLE IX Portacaval shunt model-jejunal protein synthesis

\begin{tabular}{llll}
\hline \multicolumn{5}{c}{ Protein synthesis } \\
\cline { 2 - 4 } Group & $\begin{array}{l}\text { Fractional rate } \\
(\% / d)\end{array}$ & $\begin{array}{l}\text { mg/d/g } \\
\text { organ wt }\end{array}$ & $m g / d$ \\
\hline 1 (control) & $117(25)$ & $139(32)$ & $75(17)^{\star}$ \\
2 & $146(34)$ & $160(47)$ & $110(28)$ \\
3 & $114(16)$ & $131(22)$ & $104(20)$ \\
4 & $109(20)$ & $121(22)$ & $115(13)$ \\
\hline
\end{tabular}

${ }^{\star} \mathrm{p}<0.01 v$ groups 3 and 4 . Values expressed as mean (SD).

In the portacaval shunt model, no significant differences were seen either in final weights, urea excretion, or faecal losses of protein, $\alpha$ amino nitrogen or fats although the weight of jejunal samples increased with increasing MCT intake (Table VIII). The fractional rate of protein synthesis and total rate of protein synthesis in the jejunum showed no significant differences (Table IX). No anatomopathological differences were seen in the small intestine. Takase $e t a l^{6}$ studied the effect of MCT on brush border membrane bound enzyme activity in rat small intestines and concluded that MCT (compared with lard or corn oil) increased microvillus phospholipid of the jejunal mucosa, and, unlike LCT, did not suppress the activity of mucosal microvillus membrane enzymes. Weinberg et $a l^{7}$ studied the efficacy of MCT, LCT, and dextrose on intestinal adaptation and concluded that, in general, absorptive function was better maintained by dextrose and MCT than LCT in jejunum or ileum. MCT did not result in more noticeable adaptation of the intestine, compared with LCT or dextrose. Vanderhoof et $\mathrm{al}^{8}$ studied the effect of a high percentage MCT diet in mucosal adaptation after massive bowel resection in rats and showed that mucosal weight in the proximal bowel and mucosal sucrase activity was decreased (83\% MCT $v 40 \%$ MCT).

In conclusion, the route of administration of MCT is probably extremely important, for the nutrition of enterocytes. Although a high proportion of MCT ( $>80 \%$ lipid) offers no advantage for jejunal mucosa and produces undesirable effects, its effect on jejunal mucosal protein synthesis depends on the metabolic state. We have shown that jejunal mucosal mass correlates with the MCT content of the diet, but this does not seem to be related to rates of protein synthesis in that tissue. In contrast, enzyme activity (alkaline phosphatase and sucrase) in the brush border membrane and the concentration of phospholipids in the microvilli correlate with dietary MCT intake. We would therefore propose that brush border membrane and enzyme changes are of significance in mediating the positive effects of a high oral intake of MCT, on mucosal cellularity.

1 Schwartz S, Farriol M, Rodríguez R, García-Arumí E, Padró $\mathrm{JB}$, Vente PE. Influence of the qualitative composition of enteral diets on liver and jejunal mucosa protein synthesis. $\mathcal{f}$ Clin Nutr Gastroenterol 1986; 1: 73-8.

2 Schwartz S, Farriol M, Balcells J, Murio JE, Garcia-Arumí E, Gemar E, et al. Effect of different MCT/LCT ratios on protein synthesis in injured rats fed parenterally. Res Esp Fisiol 1991; 47: 81-6.

3 Schwartz S, Farriol M, Garcia-Arumi E, Afonso JJ, Rodriguez $R$. Influence of the MCT/LCT ratio in enteral nutrition on the liver and jejunal mucosa protein synthesis in post-surgical stress. $f$ Clin Nutr Gastroenterol 1987; 2: in post-s.

4 Farriol M, Balcells J, Schwartz S, Murio JE, García-Arumí E, Bonnin J. Influence of fat emulsions in parenteral nutrition on visceral protein synthesis: study in hepatectomized rats. Rev Esp Fisiol 1990; 46: 297-302.

5 Pérez-Bartolí J, Farriol M, Balcells J, García-Arumí E, Bonnin J, Schwartz S. Influence of the MCT/LCT ratio in enteral nutrition on visceral protein synthesis following partial hepatectomy. F Clin Nutr Gastroenterol 1990; 5: 84-7.

6 Takase S, Goda T. Effect of MCT on brush border membrane-bound enzyme activity in rat small intestine. $\mathcal{F}$ Nutr 1990; 120: 969-76.

7 Weinberg LM, Pusateri JPJ, Levine GM. Comparison of different caloric substrates (MCT, LCT and dextrose) on
intestinal adaptation in the rat. Gastroenterology 1989; 96: intestinal

8 Vanderhoof JA, Grandjean CJ, Kaufmann SS, et al. Effect of high percentage of MCT on mucosal adaptation following massive bowel resection. $\mathcal{f}$ Parent Enteral Nutr 1984; 8: 685-9. 